\title{
EDUGAME4CITY. A Gamification for Architecture Students. Viability Study Applied to Urban Design
}

\author{
Ernest Redondo $^{1,3(\bowtie)}\left(\mathbb{D}\right.$, David Fonseca ${ }^{2,3}(\mathbb{D}$, \\ Mónica Sánchez-Sepúlveda ${ }^{2,3}$ (D), Héctor Zapata ${ }^{1,3}$ (D), \\ Isidro Navarro ${ }^{1,3}$ (D), Lluís Gimenez ${ }^{1,3}$ (D), \\ and Miguel Angel Pérez ${ }^{1,3}$ (D) \\ ${ }^{1}$ Universitat Politècnica de Catalunya-BarcelonaTech, 08028 Barcelona, Spain \\ \{ernesto. redondo, hector. zapata, isidro. navarro, \\ lluis.gimenez\}@upc.edu, maps@azc.uam.mx \\ 2 Arquitectura La Salle, Universitat Ramón Llull, 08022 Barcelona, Spain \\ \{david. fonseca, \\ monica. sanchez-sepulveda\}@salle.url.edu \\ 3 Universidad Autónoma Metropolitana, Unidad Azcapotzalco, \\ 02200 Ciudad de México, Mexico
}

\begin{abstract}
Hereby we present the first results of a Financed Research Project that focuses on the use of (Serious games) SG for training future architects and urban planner in the urban design context. After the first viability studies and tests in the creation of urban scenarios at intermediate scale, virtual simulation, vegetative environment and lighting, as well as basic gamification, the complete development of the teacher's methodology proposal of the research project is outlined. First five urban scenarios have been selected in which the students of Máster y Grado de Arquitectura of the ETSABarcelona-UPC of landscape and urban design have developed of urban intervention projects from the local administration and neighborhood associations. These projects have been completed subsequently in different optional courses ICT, in which 3-D virtual scenarios have been created and rehearsed under a first basic gamification. Following with the project it has continued with other courses of Architectonic Representation degree, where final settings and designs have been created, according to the students' interest in using Virtual Reality Technology. Afterwards the virtual models and scenarios were transferred to La Salle-Barcelona URL Architecture students in different courses of Representation tools, in order to continue with advanced gamification, HMD and analysis of its usage and their motivation. The results of these instructed processes have reached the administration, neighbors, professionals and general public.
\end{abstract}

Keywords: Gamification - Urban design - Educational research · Interactive learning environment 


\section{Introduction}

The work hereby presented is part of the project BIA2016-77464-C2-1-R \& BIA201677464-C2-2-R7/AEI-EU FEDER, both of the National Plan for Scientific Research, Development and Technological Innovation 2013-2016, Government of Spain, focused in the use of SG (Serious Games) when training future architects and urban planner in the area of urban design. It is a complement of another work that focuses in using strategies for citizen's participation of future public spaces users.

This subproject is coordinated with the previously mentioned one, it is titled EDUGAME4CITY and has been created by the following research groups, ADR\&M, Architecture, Design, Representation \& Modeling of the Universitat Politècnica de Catalunya BarcelonaTech (UPC) and GRETEL, Group of Research in Technology Enhanced Learning from the Architecture La Salle Center, Universitat Ramón Llull, (URL), Barcelona, funded by the National Plan for Scientific Research, Development and Technological Innovation 2013-2016, Government of Spain.

The first part of the communication is the introduction and general presentation of the project. The second part shows the current status of VR (Virtual Reality) usage in the gamification of serious urban games, applied to the processes of training future architects and urban planner. The third part describes the methodology of this work that includes: various experiences from the research team when using SG (Serious Games) applied to reinforce ICT (Information and Communication Technologies) usage in the architectonic educational field. In addition, the methodology for diverse urban scenarios designs is explained as well as their gamification. All these within the study plan of a master's degree in the ETSAB, Superior Technical School of Architecture from Barcelona (Escuela Técnica Superior de Arquitectura de Barcelona), the Polytechnic University of Catalonia-BarcelonaTech (Universitat Politècnica de CatalunyaBarcelona Tech) and from the La Salle-Barcelona Architecture center from Llull Ramon University (Centro Arquitectura-La Salle-Barcelona de la Universidad Ramón LLull). In the fourth part our conclusions are explained, and the first results of the project are discussed, since it is still in the execution phase.

In order to understand better this project, we will begin by explaining in complete summary both subprojects. The project is a cross-sectional research at the intersection of computer science and urban policies in the cities of the future, where public participation is crucial. It fits the challenge defined in the "Social changes and innovations" theme, whose five main scientific and technical priorities perfectly match our gamification for urban design proposal. For the study of the working hypotheses, we have identified four main action areas: 1 . Focused on the training and interaction with students in an area with a substantial visual component as well as social impact such as Architecture, specially urbanism in the design of urban public spaces. 2. The education of Multimedia Engineers, where gamified processes using ICTs will be designed and implemented. 3. Focused on the emotional component of the users of the project. The motivation and degree of satisfaction about the use of ICT and the gamified proposal of students, professionals and the general public. 4. The study and the improvement of public participation involvement in this kind of projects and proposals. Although some precedents of gamification and public participation in urban planning processes exist, 
there are none on urban design. Neither exists an experience involving formal and informal education processes of future architects. There is not a single example with such degree of realism in the definition of the virtual environment or visual immersion. In addition, none of them did evaluate scientifically the motivation and user satisfaction, or the effectiveness and efficiency in an academic setting of the integrative and collaborative urban design processes.

The main hypothesis of the project is based in proving the following affirmation: "The implementation of virtual gamified strategies in the field of urban design will provide an improvement in public participation since they are a more dynamic, realistic and agile collaborative environment, thanks to the augmented and immersive visual technologies". In addition, a secondary hypothesis is defined: "gamified strategies for the comprehension of three dimensional space improve the spatial competences of nonexpert users (general public) as well as students and professionals, providing a greater motivation in their use and a higher degree of satisfaction". The general objective of this work consists on promoting the use of digital technologies, in particular to evaluate the inclusion of serious games strategies and virtual reality in several areas of formal and informal teaching of collaborative urban design, in order to improve it, streamline it and increase its positive social impact. The other objectives of the project are: test and assess the teaching of urban design using collaborative design, immersive ICTs, gamification and public participation. Simulate, test and evaluate public participation in urban projects through online gamification.

\section{The State of Art}

\subsection{Serious Games Applied to Urban Design}

Some examples of gamification and citizen participation can be found in planning processes, but there are none in urban design. Neither are there any examples in the formal and informal processes of teaching future architects. No example has such a high level of realism in the definition of the virtual scenario, nor such a high level of visual immersion. None of them scientifically assessed the motivation and satisfaction of users, nor the efficacy and efficiency in an academic simulation of integrated and collaborative processes of urban design.

The main hypothesis of this project is based on proving the statement: the implementation of "gamified" strategies in the area of urban design will improve citizen participation as gamification creates more dynamic, real, flexible collaborative environments through augmented and immersive visual technologies. Some examples of the use of gamification in urban planning processes are associated with citizen participation. One of these is Blockholm: a Minecraft-based planning game on Stockholm. A total of 100,000 users, urban design technicians and experts, and citizens were invited to participate in Blockholm [1].

Other examples are Play the City, from the Play the City Foundation, [2] implemented throughout 2012 in various cities in Holland, Belgium, Turkey and South Africa and based on a game like World of Warcraft, or the use of the game SimCity in its various versions in urban planning workshops, notably in Cape Town in 2013. 
Finally, we can mention the experience of gamification of the urban planning process in the game PLANIT, [3] developed in 2013 in Detroit. This is an internetbased game designed to increase the attractiveness of citizen participation, by making planning fun. However, ultimately the game is an organiser of mind maps of how users understand the city. The aim is to involve elderly people and challenge them to give their opinions of urban planning and bring new residents into the process. In this regard, the experience is closer to our approach, given that challenges have been defined for users to resolve, which generate complementary information prior to creating the design, which can be interpreted as support or rejection of a proposal.

\subsection{Serious Games Applied to Urban Design for Architect's Education}

Architects are trained to have the ability to build abstract relationships and understand the impact of ideas based on research and analysis, including the facility with a wider range of media used to think about architecture and urbanism including writing, research skills, speaking, drawing and model making. Linked to these skills are visual communication skills [4-7]. Architecture students tend to express primary by visual representation and throughout their academic career learn to represent through various representation technologies incorporating them in their design process to better communicate their proposals.

Technologies that model in 3D, Virtual Reality and even video games, represent progress to enhance the capacity of spatial and graphic vision and therefore facilitate the process of project conception [8]. Architects should have the ability to use appropriate representational media, such as traditional graphic and digital technology skills, to convey essential formal elements at each scenario of the programming and design process [9].

The use of ICTs in educational methods is defined in the courses of many undergraduates and master's degrees, including the architecture degree $[10,11]$. From an educational perspective, these methods are applied to enhance the acquisition of spatial competences to analyze the visual impact of any architectural or urban project [12]. Architecture students must learn to be proficient in these representation technologies throughout their studies $[13,14]$.

For this paper, we will focus on the new interactive systems based on video games. Video Games/Gamified Systems have tasks that have a high spatial component (rotate, move, scale, etc.) are present in video games, as well as in serious games applied to the visualization of complex models, where we can find actions in which the user must move the character in a multitude of possible combinations $[15,16]$. These interactive applications have favored the performance and speed of learning as well as the personal and intrapersonal skills of students. The contents that are based on these formats are closer to the means of everyday use of students and end-users. For this reason, this type of system is more attractive, increase the motivation and favor the performance [17].

For this, we created a virtual reality game in which through interactive elements, the students shaped the urban public space, following previous case studies focused on similar approaches [18]. Students were in charge of modelling the space with different software and then analyzing the proposed methods, their profile and learning experience. Students were first introduced to emerging technologies such as augmented and 
virtual reality in a course that is focused on using videogame technology for architecture representation [19], taking advantage of improvements in real-time rendering to produce interactive content.

\subsection{Digital Technologies (DT) in Urban Design and Architectural Education}

Recent Studies [20] that can be consulted in the specialized biography are focused in adapting its contents and application using ICT in the architecture and urban design fields. This work focuses in evaluating students' profiles as well as their satisfaction and motivation when using ICT in their design processes.

From an academic perspective, ICT improves the acquisition of space skills for studying the impact of architectonic or urban projects of visual impact. Particularly in architecture and urban design courses, there is a need to evaluate if a design is appropriate before it could be built, which leads educators to reconsider how students represent the designs and learn how to perform this evaluation.

Therefore, it is important that students develop skills in different emerging technologies so that they can integrate them in their designing process, with the purpose of better communicating their proposals and facilitate the analysis when it comes to the spaces they are designing [21].

Along the history of Architectonic Education, the comprehension and visualization of 3D spaces has been done through drawings and models, even though recently it is very common to use 3D models and virtual displays [22]. The use of these new methods is emerging due to the generation change and continuous technology improvement and development [23]. In particular, the new generations have technology knowledge and are familiarized with the use of computer systems and immersive visualization, the VR through HMD.

In education, gamification is a new standpoint that transforms the way in which students deal with the information they learn. In the specific context of Urbanism, where the scenarios to be designed are quite extensive and are planned to be visited and discovered from multiple points of view, VR along Serious Games SG, seem to be a natural and logic solution. If we add the immersive capacity and the possibility to modify the design in real time and before our own eyes and ears, because VR is multisensory, the educational paradigm change is very big.

That is the reason why we have considered this research project, in a teaching context, in master's degree studies from ETSAB-UPC from La Salle-Barcelona Architecture center (Centro Arquitectura La Salle-Barcelona), in which urban design is one of the identity brands of the Catalonian architectonic culture.

\section{Methodology}

\subsection{Generating the 3D Urban Scenario and the Urban Design Studio}

The urban projects we work on, promoted by the Barcelona Metropolitan Area, aims to generate spaces that are designed to meet what the users' wants: spacious, pleasant 
spaces with vegetation, with dynamic uses, spaces for children's games, urban gardens, lighting, recreational and cultural activities, among others.

The 4-5 selected sites, streets and squares that are closed to the vehicle for the pedestrian and outdoor activities of the neighbors. The objective is to create a large public space that prioritizes the people instead of the vehicles [24]. By closing the street to vehicles and allowing it to pedestrians, the program to be situated there is design according to their criteria. Collaboratively, along with the neighbors, was stated the following conditioners: Address the street primarily to pedestrians; give spaces for a stay and neighborhood living. Increase the low vegetation while maintaining the alignment of trees typical. Increase the surface of rainwater catchment on the terrain. Establish criteria for the location of furniture and services (garbage bins, bar terraces, etc.).

We work with two groups of students. In the first group, the students were selected from a 4th year subject at the Superior Technical School of Architecture of Barcelona, Polytechnic University of Catalonia (UPC). They used Sketch Up for modelling and rendering applications like, 3DSmax-Arnold, Sketch Up-Vray, Cinema4D-Corona or Blender-Cycles/EVEE for creating visual simulations or renders; real time render engines like Twinmotion or Lumion for creating interactive virtual scenarios, and game engines like, Unreal or Unity with HMD for creating the interactive virtual environment of the space. The second group has students from a 2nd year subject at the Superior Technical School of Architecture of La Salle, Ramon Llull University, where the students used 3DMax and Unreal reproduced the same spatial area that the first group and gamify the scenarios using HMD. In this section the scenarios here are optimized and completed in their functionalities by the students and teachers of the degree in Multimedia Engineering of La Salle-Barcelona-URL.

In the other communication presented here, the citizens participation is described, according to the initial hypothesis, only one test was carried out in the neighbor's association premises from the first studied environment. The Illa Germanentes of Barcelona. Where the reorganization project content was shown on a virtual reality device HMD (Head Mounted Display) and a laptop during just one visit. Users visualize the hyperrealist interactive urban environment where the urban proposal is developed. Before that first failure a contingent plan was applied which better results are widely described in the bellow quoted document under the acronym GAME4CITY.

On the other hand, for the study performed in this research, the number of students involved was larger. Overall 1300 students from the ETSAB-UPC have participated and 210 from La-Salle-URL Architecture.

\subsection{Project Development Study in the Architecture and Urbanism Education}

Continuing with the project, the relation among the courses involved from Architecture and Urbanism are explained. Each course contains some of the images that portray the work carried out by students in regard to the project theme and a description of their course, level, year or semester, number of students, scenario or urban environment studied, and technology apps used. 


\section{Subjects at the Bachelor and Master in Architecture Level at the ETSAB-UPC.}

The subjects where teaching related to this project has been taught are the following. MBLandArch. Subject. Landscape Design 3. Course 2. Compulsory. Semester 1 Credits ECTS, 6. Year. 2017-2018. Urbanims Department. Max. 25 Students for group. Groups 1. Urban scenario 1. Superblock Germanetes-Barcelona. Action. Urban design and furniture project based on a preliminary project of the (Metropolitan Area of Barcelona). AMB Superblock Barcelona and the Neighborhood Association of "L'Esquerra de L'Eixample". Traditional architectural drawing CAD, Freehand Drawing, Digital Collage, etc. (see Fig. 1).
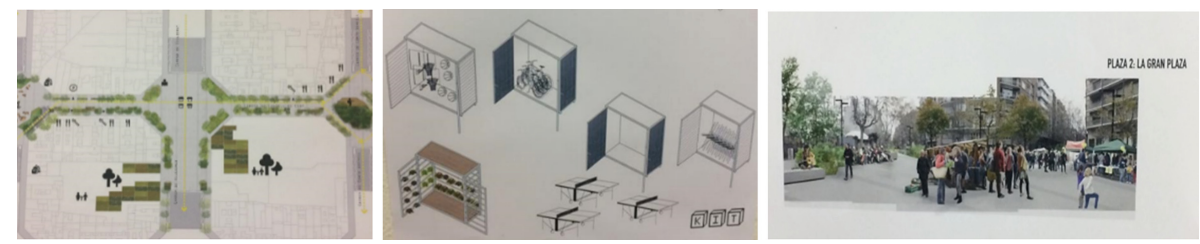

Fig. 1. Images of the intervention project in Scenario 1

GArqBCN. Degree in Architecture Studies. Subject: Urban Design III. "Public Space”. Course 3. Compulsory. Semester 1. Credits ECTS, 5. Year. 2018-2019. Urbanism Department. Maximum 180 students per group. Groups 2. Urban scenario 3. Cataluña Square and Generalitat Square. Sant Boi de Llobregat. Action. Urban design and reorganization project based on two urban plans promoted by the Sant Boi City Council and the neighborhood associations "El Poblet" and "La Plaça Catalunya". Graphical Techniques CAD, Freehand Drawing, Digital Collage, (see Fig. 2).

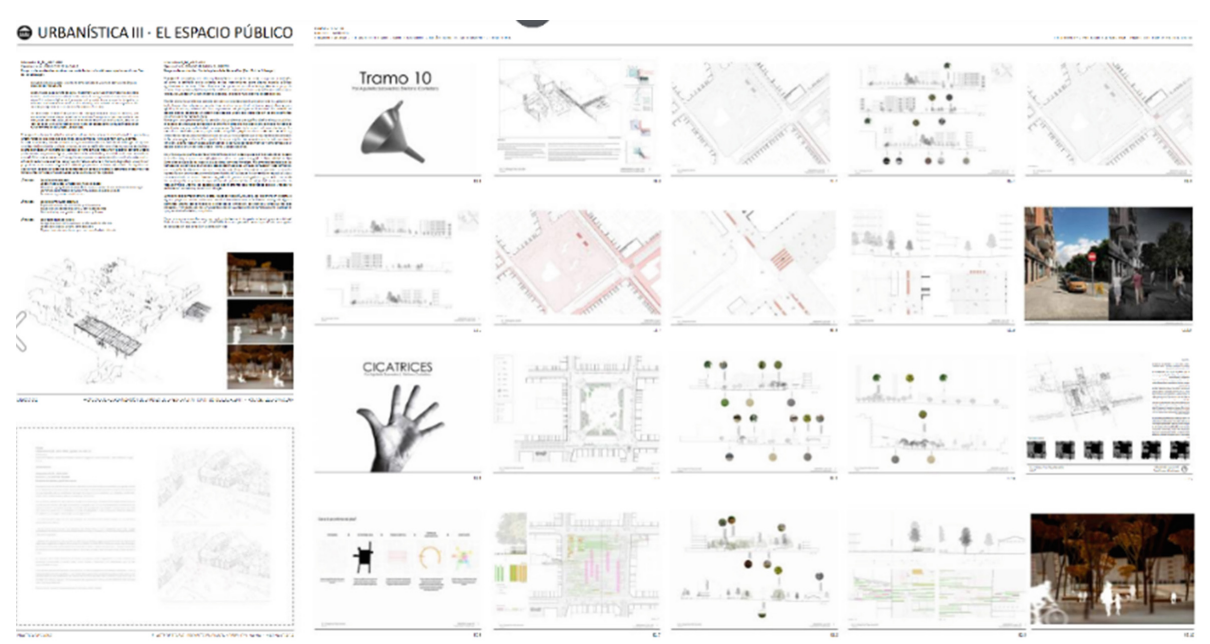

Fig. 2. Images of the intervention project in Scenario 3 
To conclude, the work is being done for the last urban scenario planned for this project. We have pending the rehearsal with the new touch screen system in the Gameplay Exhibition at the CCCB, in the Rambla Modolell de VIladecans scene, where the neighbors and shopkeeper's association is immersed in a participative process for its redesign. The goal is to place our videogame in the city hall of this neighborhood for a long period of time so that users can engage in the design itself based on a municipal draft.

GArqBCN. Degree in Architecture Studies. Subject: Multimedia. Architectural Information and Communication Technologies ICT. Elective. Semester 2. Credits ECTS 3. Year. 2017-2018. Architectural Representation Department. 15 Students per group. Groups 1. Subject that served to conduct a feasibility study of the teaching process and based on the data obtained request the financing of the Project. Urban scenario 00. Barcelona Knowledge Campus. Conversion in residence of students the building of the ETSEIB. Construction of the 3D scenario and study of basic gamification. Reconversion in residence of students of the ETSEIB building. Construction of the 3D scenario and study of basic gamification ICT Techniques. 3D modelling. Photogrammetry, rendering, gaming with unreal-unity (see Fig. 3).
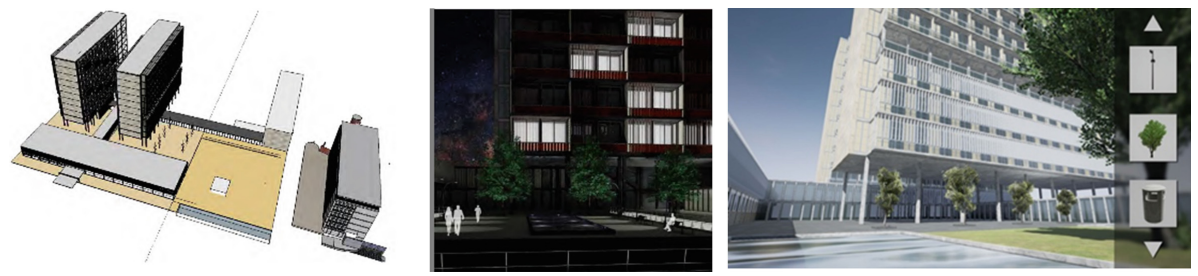

Fig. 3. Images of the basic representation and gamification project in Scenario 00. BKC. Barcelona

GArqBCN. Degree in Architecture Studies. Subject: Multimedia. Architectural Information and Communication Technologies ICT. Elective. Semester 2. Credits ECTS 3. Year. 2018-2019. Architectural Representation Department. Max. Students for group. 15. Groups 1. Urban scenario 1. Construction of the 3D scenario and basic gamification project. ICT Techniques. 3D modelling. Photogrammetry, photoscan, photomodeler, rendering, gaming with unreal-unity (see Fig. 4).

Workshop UPC+URL. Gamification for urban scenario. Urbanism Department + Architectural Representation Department. 2018-2019. Subject. Elective. ECTS 3. Max. Students for group. 15. Groups 1. Urban scenario 2. Plaza Baró. Santa Coloma de Gramenet. Barcelona. Action. Construction of the 3D scenario and basic gamification project based on a preliminary project defined by the City Council and the Neighborhood Association "Barri Center". ICT Techniques. 3D modelling. Photogrammetry, photoscan, photomodeler, rendering, gaming with unreal-unity (see Fig. 5).

GArqBCN. Degree in Architecture Studies. Subject: Multimedia. Architectural Information and Communication Technologies ICT. Elective. Semester 2. Credits ECTS 

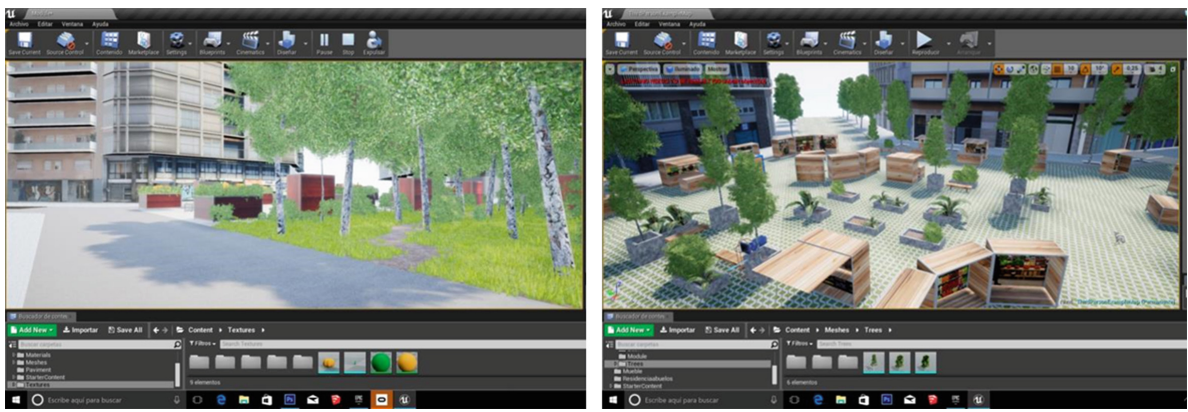

Fig. 4. Images of the Basic Gamification Project in Scenario 1. Germanetes. Barcelona
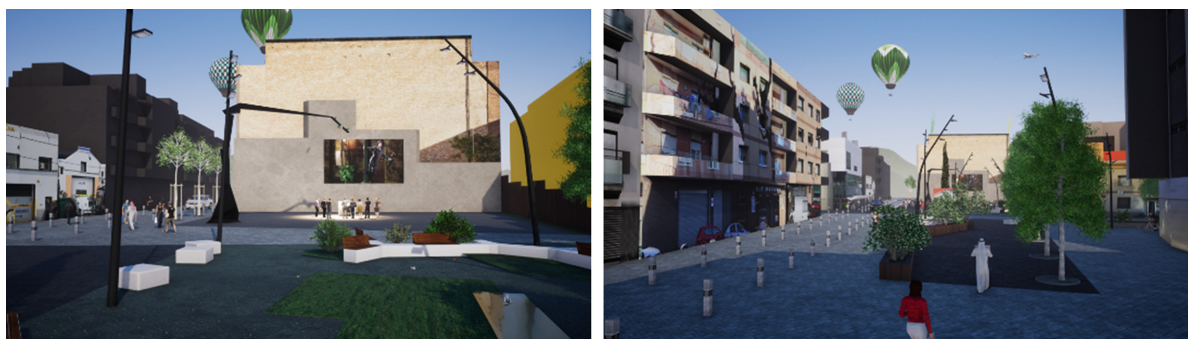

Fig. 5. Images of the intervention and virtual simulation project in Scenario 2. Sta. Coloma de G. Barcelona.

3. Year. 2018-2019. Architectural Representation Department. Max. Students for group. 15. Groups 1. Urban scenario 2. Construction of the 3D scenario and basic gamification project. ICT Techniques. 3D modelling. Photogrammetry, photoscan, photomodeler, rendering, real time rendering, gaming with Unreal-Unity (see Fig. 6).
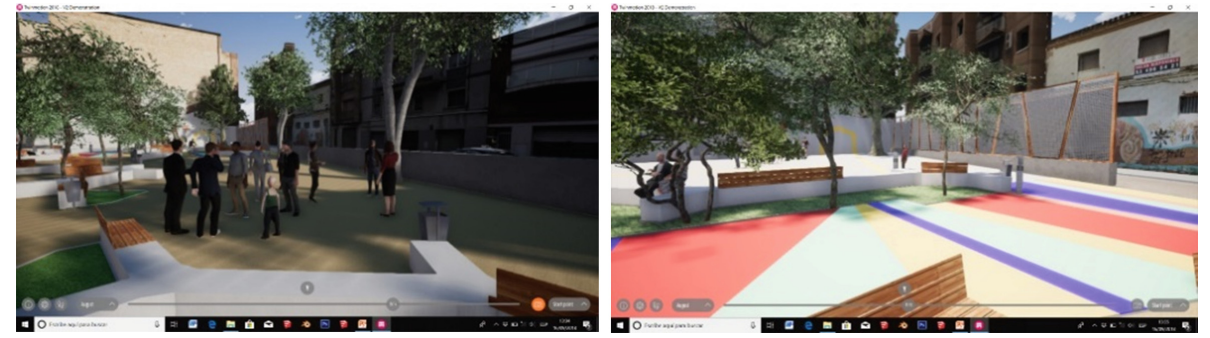

Fig. 6. Images of the intervention and virtual simulation project in Scenario 2. Sta. Coloma de G. Barcelona. 
GArqBCN. Degree in Architecture Studies. Subject: Workshop Interactive-Urbanscenario. Year. 2018-2019. Curse 4. Elective. Credits ECTS 3. Semester 2. Architectural Representation Department+Urbanism Department. Max. Students for group. 15. Groups 1. Urban scenario 2. New construction of the 3D scenario and advanced gamification project. ICT Techniques. 3D modelling, photogrammetry, rendering, gaming with unreal-unity (see Fig. 7).
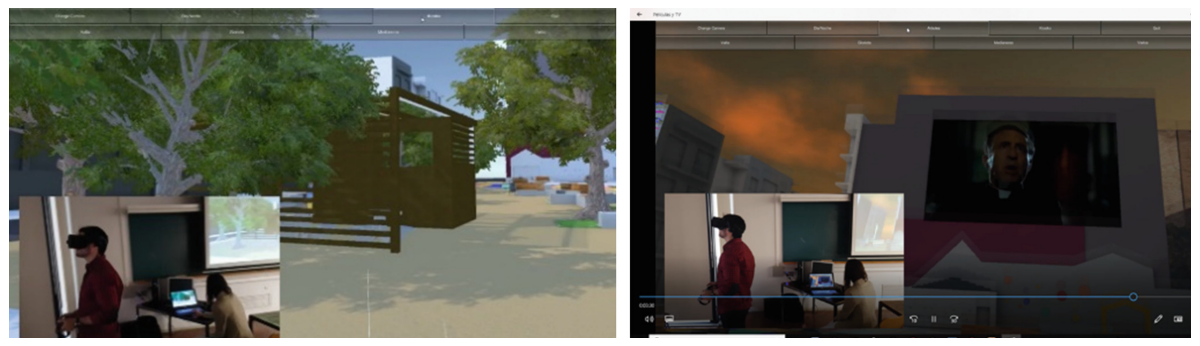

Fig. 7. Images of the Gamification Project in scenario 2. Sta. Coloma de G. Barcelona

GArqBCN. Degree in Architecture Studies. Subject: Interactive Urban scenario. Elective. Semester 1. Credits ECTS 3. Year. 2019-2020. Architectural Representation Department. Max. Students for group. 15. Groups 1. Urban scenario 5. Exhibition assembly project in the "Pati de les Dones" of the CCCB, Center of Contemporary Culture of Barcelona. Part 1. Construction of the 3D scenario. Part 2. Advanced gamification project. ICT Techniques. 3D modelling. Photogrammetry, photoscan, photomodeler, rendering, real time rendering, gaming with Unreal-Unity (see Fig. 8).
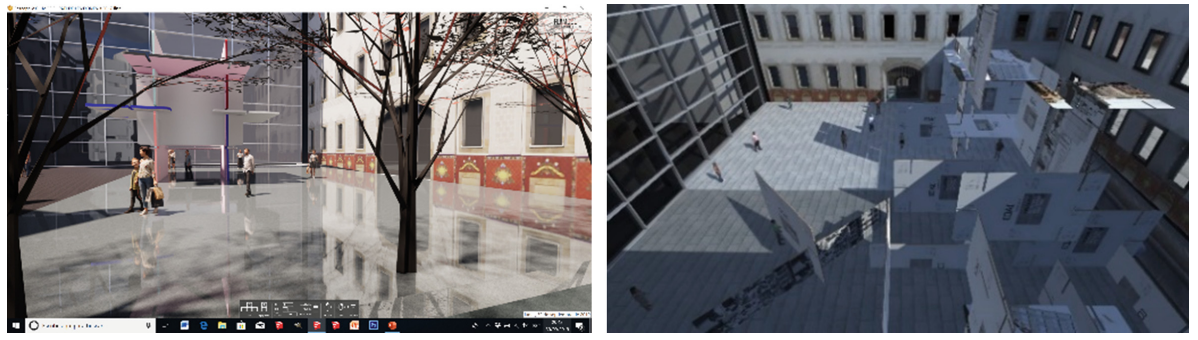

Fig. 8. Images of the virtual simulation and gamification project in scenario 5. CCCB. Barcelona.

In these optional courses, volumetric definition of 3D model textures is emphasized in the urban scenario. Just as it is defined by the municipal administration, neighbors and landscape or urbanism students, we proceed to insert new elements, evaluating its location, scale, materials, with a low level of gamification, alternating interactive navigation through a mouse when using HMD. 
As for the mandatory courses, they use the 3D model defined in the optional courses, as well as the designing projects with small changes that affect the insertion of new elements of urban furniture and remodeling of existing buildings, etc. On the other hand, the insertion of vegetative elements and nigh lighting are also included, all this in the first part of the course, using the usual rendering programs. Since the 2018-2019 course, a third exercise was included in which the modified urban scenarios are seen through a rendering engine in real time, Enscape, Twinmotion or Lumion. GArqBCN. Degree in Architecture Studies. Subject: Arquitectural Representation 3. Course 2. Compulsory. Semester 1 and 2. Credits ECTS, 5. Year. 2017-2018, S1 and S2. Architectural Representation Department. Max. Students for Group/Semester. 90. Groups 2. Urban scenario 1, studied by the students of the MBLandArch course. Subject. Landscape Design 3. ICT Techniques. 3D modelling, rendering, photomontage (see Fig. 9).
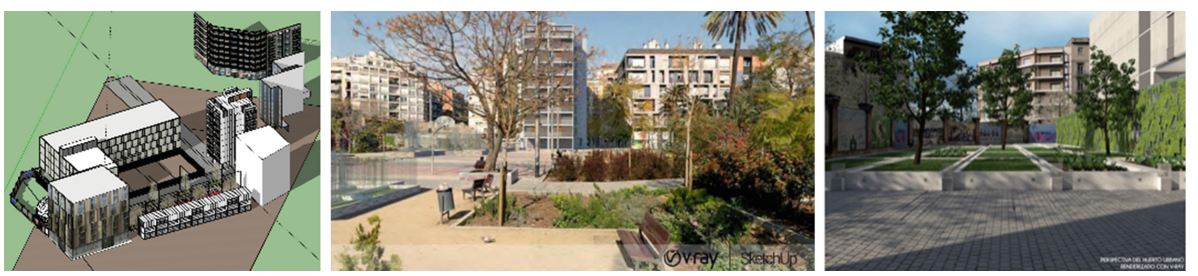

Fig. 9. Images of the virtual simulation project and setting in scenario 1. Germanetes. Barcelona.

GArqBCN. Degree in Architecture Studies. Subject: Arquitectural Representation 3. Course 2. Compulsory. Semester 1 and 2. Credits ECTS, 5. Year. 2018-2019, S1 and S2. Architectural Representation Department. Max. Students for Group/Semester. 90. Groups 2. Urban scenario 2, studied by the students of the Workshop Gamification for Urban scenario. Urbanism Department+Architectural Representation Department. 2018-2019. ICT Techniques. 3D modelling, rendering, photomontage (see Fig. 10).
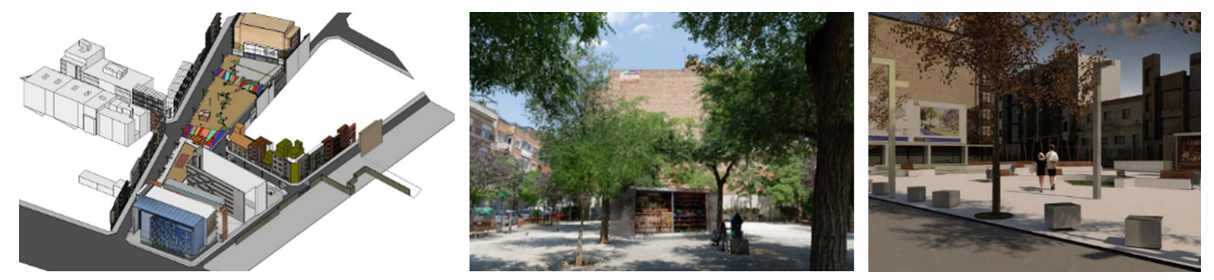

Fig. 10. Images of the virtual simulation and setting project on the scenario 2. Sta. Coloma de G. Barcelona.

GArqBCN. Degree in Architecture Studies. Subject: Arquitectural Representation 3. Course 2. Compulsory. Semester 1 and 2. Credits ECTS, 5. Year. 2019-2020, S1 
Architectura Representation Department. Students for group. 90. Groups 2. Urban scenario 3. Virtual simulation and ambience project based on an urban environment design and reorganization project developed by GArqBCN students. Subject: Urban Design III \& IV. ICT Techniques. 3D modelling, rendering, real time rendering, photomontage (see Fig. 11).
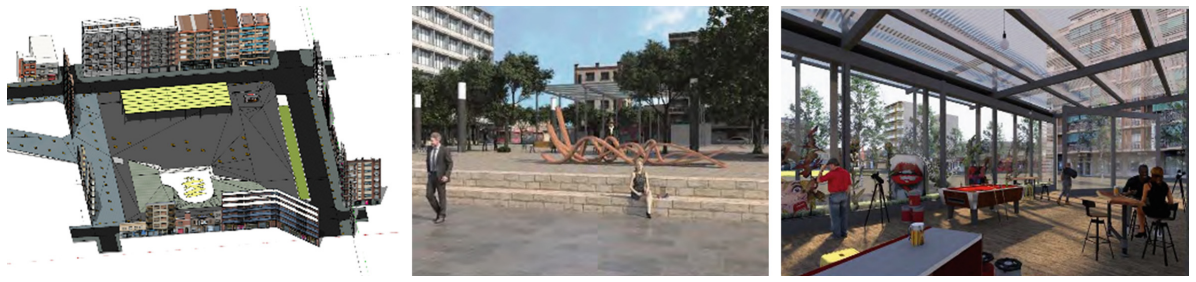

Fig. 11. Images of the virtual simulation and setting project on scenario 3. Sant Boi de Llobregat. Barcelona.

PART 1. Rendering+Visual Analysis.

PART 2. Real Time rendering methodologies in interactive urban scenarios (see Fig. 12).
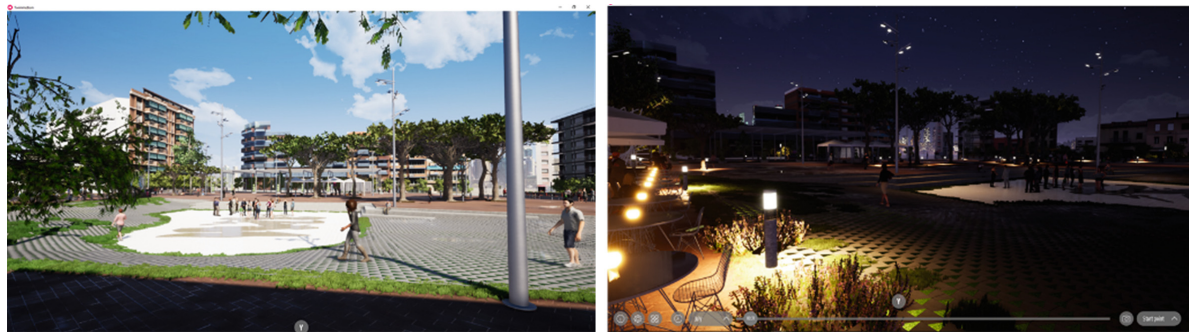

Fig. 12. Images of the virtual simulation project and interactive atmosphere on scenario 3. Sant Boi de Llobregat. Barcelona.

MBArch. Master's Degree in Advanced Studies in Architecture-Barcelona. Line of specialization: Contemporary Project. Subject: Urban Project. Ideas and Praxis. Compulsory. ECTS 5. 2 2018-2019. Students for Group. 20. Groups 1. Urban scenario 4. La Rambla Modolell. Viladecans, Barcelona. Action. Project for the reorganization of uses and redesign of urban furniture based on an urban plan promoted by the City Council of Viladecans and the neighborhood and merchant associations of "La Rambla Modolell". ICT Techniques. 3D modelling, rendering, real time rendering, photomontage. PART 1. Urban project. Ideas. Project for the reorganization of uses and redesign of urban furniture based on an urban draft promoted by the City Council and neighborhood and merchant associations. PART 2. Urban Project. Praxis. Virtual simulation project and setting. Real time rendering methodologies in interactive urban scenarios (see Fig. 13). 

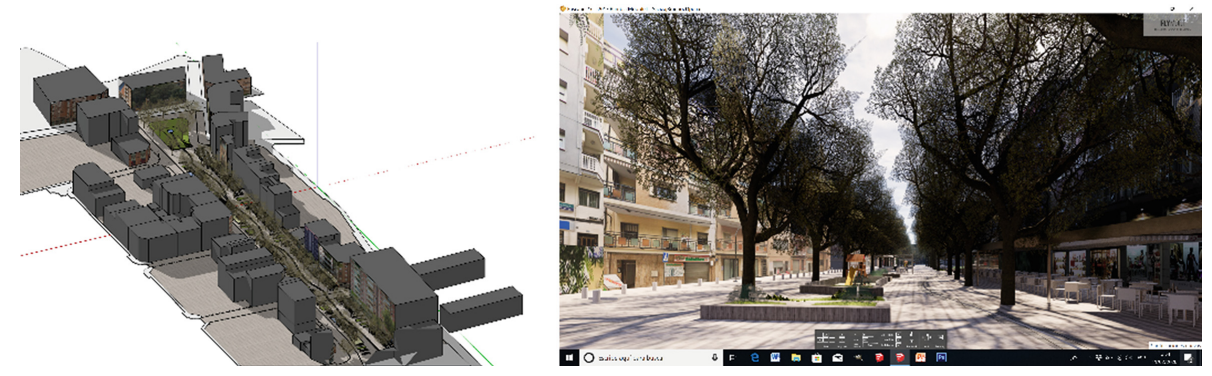

Fig. 13. Images of the virtual simulation project and interactive atmosphere on scenario 4 . Rambla Modolell. Viladecans, Barcelona.

Courses of Architecture Master's Degree in Architecture -La Salle BarcelonaURL. Courses where topics relating this project have been taught. In these subjects the Architecture-La Salle students, have the support of Multimedia instructors who also use such gamification digital tools in the process of urban design, introduction menus and interactive objects. Degree in Architecture Studies. Subject: Computer Tools. 2, Course 2. 6 ECTS. Compulsory. Semester 2. Year. 2017-2018. Max. Students for Group. 35. Groups 2. Urban scenario 1. Gamification in interactive urban scenario. Advanced gamification of urban settings with the use of HMD. ICT Techniques. 3D modelling, gamification, unreal-unity. HMD glasses (see Fig. 14).
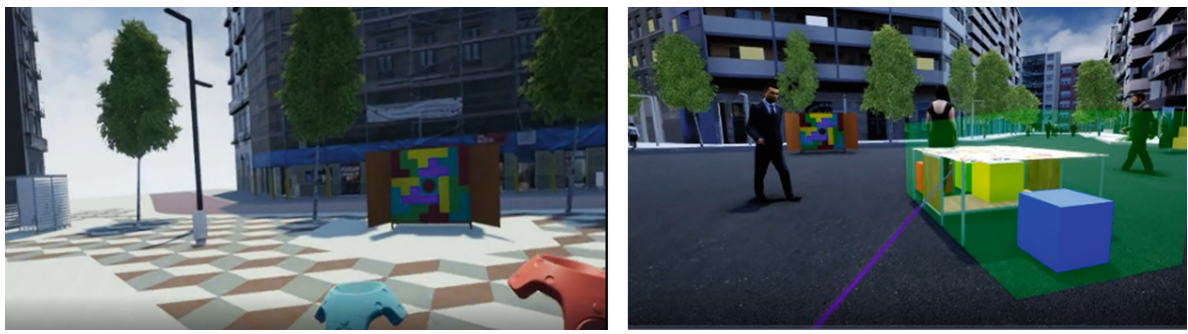

Fig. 14. Images from the Advanced Gamification Project of scenario 1. Germanetes. Barcelona.

Degree in Architecture Studies. Subject: Computer Tools. 2, Course 2. 6 ECTS. Compulsory. Semester 2. Year. 2018-2019. Max. Students for group. 35. Groups 2. Urban scenario 2. Gamification in interactive urban scenario. Advanced gamification of urban settings with the use of HMD. ICT Techniques. 3D modelling, gamification, unreal-unity. HMD glasses (see Fig. 15).

Degree in Architecture Studies. Subject: Computer Tools. 2, Course 2. 6 ECTS. Compulsory. Semester 2. Year. 2019-2020. Students for group. 35. Groups 2. Gamification in Interactive Urban scenario 3. Advanced gamification of urban settings with the use of HMD. ICT Techniques. 3D modelling, gamification, unreal-unity. HMD glasses (see Fig. 16). 

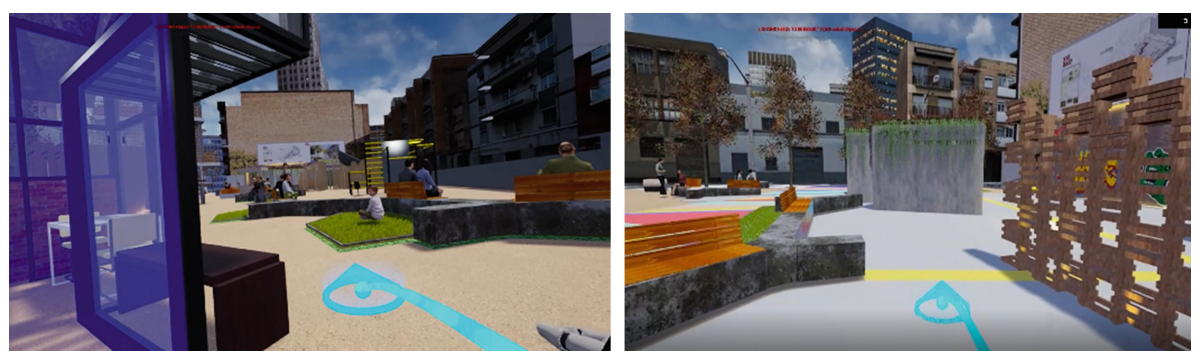

Fig. 15. Images from the Advanced Gamification Project of scenario 2. Sta. Coloma de G. Barcelona.
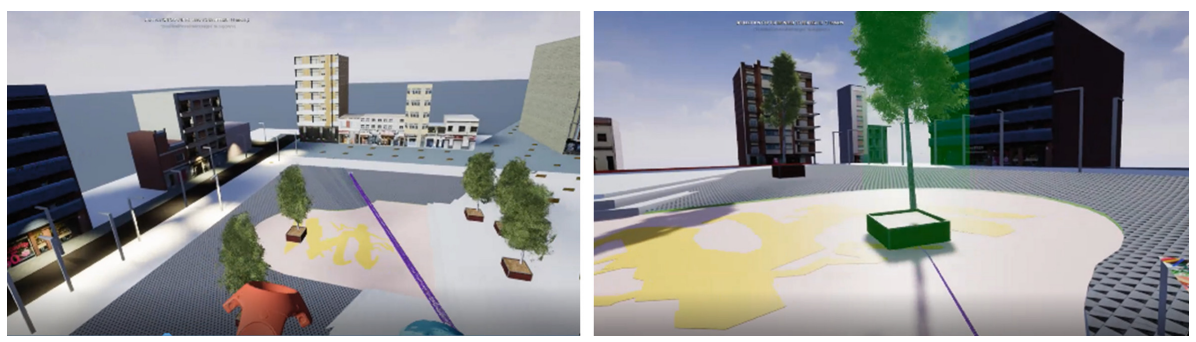

Fig. 16. Images from the Advanced Gamification Project of scenario 3. Sant Boi de Llobregat. Barcelona.

Particular attention was paid to this experiences in order to reflect the right scale of new buildings and the effect of the sun in public spaces; the right night lighting in squares and the safety feeling transmitted to the neighbors; the amount of vegetation elements to add to the projects, as well as the different paved zones hard or soft. On the other hand, the correct location of furniture elements and urban equipment is not always controlled.

\subsection{Students Courses Evaluation}

Students from ETSAB-UPC Evaluated Their Experience. Based on the data gathered from the teaching information system. UPC University Using the telematics survey model has performed these questionnaires every six months for all the courses. These surveys are for students taking the classes who volunteer to participate.

Aspects to consider by the University: in the context of surveys on subjects and teaching activity, and in the face of the problem of low participation in surveys, we saw the need to create a model in order to statistically define the minimum responsiveness to be able to consider survey results as representative of teaching performance and subjects. The purpose of this work is to provide a criterion to ensure that the hypotheses tested can be resolved with sufficient guarantees of sensitivity and specificity. It is decided to propose a hypothesis test on finite size population and with variable size 
sample. The methodology developed must allow the diagnostic test to be characterized based on its ability to correctly decide the test. Based on the number of registrations and responses, the reliability of the survey is classified in bad/regular/normal/very good/excellent. Then: both faculty and subject surveys will be eliminated automatically with confidence regular or bad. In this case the number of registrations and responses is normal or very good.

The questions about the courses considered in the survey are: Q1 Have the subject contents been interesting? Q2. Does de program evaluation align with the objectives and level of the course? Q3. Am I overall satisfied with the course? The evaluation criteria for the questions are as follows: Q1: The average response per course or subject for Q1. In a scale of 1 (Strongly Disagree) to 5 (Strongly Agree). Answer-Q1. Number of answers to each question Q1. Participation \%. Question 3 is used as the core to evaluate its quality and continuity (Table 1).

Table 1. Evaluation of the compulsory and optional courses of architectural representation at the ETSAB-UPC

\begin{tabular}{l|l|l|l|l|l|l|l|l|l|l}
\hline \multicolumn{1}{l}{ Subject: Architectural Representation 3} \\
\hline Subject & Year & Sem. & Stud. & Val. P1 & Val. P2 & Val. P3 & R. P1 & R. P2 & R. P3 & $\%$ \\
\hline Arch. Rep 3 & $2016 / 17$ & 2 & 126 & 4,03 & 4,17 & 4,03 & 29 & 29 & 29 & 23,02 \\
\hline Arch. Rep 3 & $2017 / 18$ & 1 & 223 & 3,81 & 3,68 & 3,39 & 88 & 87 & 87 & 39,46 \\
\hline Arch. Rep 3 & $2017 / 18$ & 2 & 101 & 3,32 & 3,81 & 3,37 & 28 & 27 & 27 & 27,72 \\
\hline Arch. Rep 3 & $2018 / 19$ & 1 & 163 & 4,05 & 3,66 & 3,48 & 58 & 58 & 58 & 35,58 \\
\hline Arch. Rep 3 & $2018 / 19$ & 2 & 111 & 3,91 & 3,74 & 3,62 & 35 & 35 & 34 & 31,53 \\
\hline
\end{tabular}

The type of work addressed by students, as well as traditional virtual simulation methodologies and some Real Time rendering for the course, Architectural Representation 3,57 above 5 is Good or Very Good. This improvement is done in parallel with Real Time rendering programs that speed up the processes and allows you to look over the scenarios internally and discover different points of view. In the case of the multimedia course where basic gamification is used in urban settings, the results for question 3 are greater than 4 over 5 in average. In this case the need to program an urban scenario by the students and its difficulties, was not always properly solved by them. The participation rate, even though low, is considered representative by the UPC according to the criteria previously outlined and due to the optional character of the surveys.

Experience Evaluation by Students from the Architecture LaSalle-Barcelona-URL. La Salle URL's case in evaluating the experiences has been done by a research team, based in specific questionnaires documented in different publications. [Experts Systems] Utility perception of interactive and gamified systems: Post-test.

The structure of the post-test is based on the International Organization of Standardization (ISO) 9241-11 and make achievable to assess the usability of the VR technology and interactive-gamified methods in educational environments. Table 2 shows the students' main perceptions (P1 to P7), including their valuation the proposed 
Table 2. Subject: multimedia. ICT for the architecture.

\begin{tabular}{l|l|l|l|l|l|l|l|l|l|l}
\hline Subject & Year & Sem. & Stud. & Val. P1 & Val. P2 & Val. P3 & R. P1 & R. P2 & R. P3 & $\%$ \\
\hline MultiM ICT & $2016 / 17$ & 2 & 19 & 4,33 & 3,67 & 4,00 & 3 & 3 & 3 & 15,79 \\
\hline MultiM ICT & $2017 / 18$ & 2 & 10 & 4,75 & 4,75 & 4,75 & 4 & 4 & 4 & 40,00 \\
\hline MultiM ICT & $2018 / 19$ & 1 & 15 & 4,20 & 3,80 & 3,80 & 5 & 5 & 5 & 33,33 \\
\hline
\end{tabular}

methodology, perceived usefulness, and level of satisfaction. In addition, we have incorporated their assessment of gamification processes (GA UPC students. GB URL students). GA students del Workshop Gamification for urban scenarios. Urbanism Department+Architectural Representation Department. 2018-2019. UPC-URL (Table 3).

The best-valued aspect is the P1 that affirms the importance of 3D visualization for the understanding of space, but the motivation of the students for their use in architectural projects can be defined as low. An aspect that is related to the difficulty of use and needs to perceive the quality of the model (P5), in mobile devices with small screens. The perception of the usefulness of sound and the gamification of the interaction are the aspects least valued by the students, and that reflect as there was a lack in the need to take into account other variables of the project in the academic presentations beyond of the visual. Just the opposite of users who are not experts in the development or education of architectural or urban projects, an aspect that reflects a gap to be resolved internally in current educational plans.

Table 3. Means of perception and gamification by students group

\begin{tabular}{l|l|l|l|l|l|l}
\hline Variables & \multicolumn{3}{l|}{ Mean GA (34, 21 m-13 f) } & \multicolumn{3}{l|}{ Mean GB (39, 12 m-17 f) } \\
\hline Perception of the proposal & GA & Males & Females & GB & Males & Females \\
\hline $\begin{array}{l}\text { P1 - Digital 3D visualisation of } \\
\text { Architecture/Urban projects is } \\
\text { very important to understand the } \\
\text { space }\end{array}$ & $\mathbf{4 . 2 8}$ & 4.13 & 4.44 & $\mathbf{4 . 2 8}$ & 4.33 & 4.24 \\
\hline $\begin{array}{l}\text { P2 - The use of Virtual Reality } \\
\text { to display A/U projects is useful } \\
\text { for their understanding }\end{array}$ & $\mathbf{4 . 0 8}$ & 4.38 & 3.78 & $\mathbf{4 . 0 2}$ & 4.17 & 3.88 \\
$\begin{array}{l}\text { P3 - Based on the proposal } \\
\text { used, I am motivated to use VR } \\
\text { in my future projects for their } \\
\text { presentation and understanding }\end{array}$ & $\mathbf{3 . 7 2}$ & 4.00 & 3.44 & $\mathbf{3 . 7 7}$ & 3.67 & 3.88 \\
$\begin{array}{l}\text { P4 - Models scale are suitable } \\
\text { to manipulate virtual elements }\end{array}$ & $\mathbf{3 . 7 3}$ & 3.56 & 3.89 & $\mathbf{4 . 2 4}$ & 4.25 & 4.24 \\
\hline $\begin{array}{l}\text { P5 - The materials, textures, and } \\
\text { lighting of a virtual environment }\end{array}$ & $\mathbf{3 . 2 4}$ & 3.25 & 3.22 & $\mathbf{3 . 4 2}$ & 3.67 & 3.18 \\
\hline
\end{tabular}


Table 3. (continued)

\begin{tabular}{|c|c|c|c|c|c|c|}
\hline \multirow{2}{*}{$\begin{array}{l}\text { Variables } \\
\text { Perception of the proposal }\end{array}$} & \multicolumn{3}{|c|}{ Mean GA $(34,21 \mathrm{~m}-13 \mathrm{f})$} & \multicolumn{3}{|c|}{ Mean GB $(39,12 \mathrm{~m}-17 \mathrm{f})$} \\
\hline & GA & Males & Females & GB & Males & Females \\
\hline \multicolumn{7}{|l|}{$\begin{array}{l}\text { must always be the most } \\
\text { realistic possible }\end{array}$} \\
\hline $\begin{array}{l}\text { P6 - The existence of } \\
\text { background music is better and } \\
\text { satisfies the user in the } \\
\text { interaction with virtual spaces }\end{array}$ & 2.47 & 2.38 & 2.56 & 3.35 & 3.75 & 2.94 \\
\hline $\begin{array}{l}\mathrm{P} 7 \text { - The visualisation device } \\
\text { has a considerable influence in } \\
\text { the virtual quality perception }\end{array}$ & 4.08 & 4.38 & 3.78 & 3.79 & 4.17 & 3.41 \\
\hline \multicolumn{7}{|l|}{ Gamification indicators } \\
\hline $\begin{array}{l}\text { G1 - The use of gamified } \\
\text { environments (with missions } \\
\text { and achievements) are better } \\
\text { than simple free navigation in a } \\
\text { virtual space }\end{array}$ & 3.77 & 3.88 & 3.67 & 3.28 & 3.33 & 3.24 \\
\hline $\begin{array}{l}\text { G2 - Playing games, I prefer } \\
\text { one-to-one games vs. } \\
\text { multiplayer environments }\end{array}$ & 3.16 & 2.88 & 3.44 & 2.85 & 2.75 & 2.94 \\
\hline $\begin{array}{l}\text { G3 - I consider that using } \\
\text { games in educational } \\
\text { environments can help to } \\
\text { understand better the typology } \\
\text { and correction of the materials } \\
\text { used in the scenes }\end{array}$ & 3.80 & 3.81 & 3.78 & 3.10 & 3.08 & 3.13 \\
\hline
\end{tabular}

\section{Conclusions}

With the information gathered until now and since the Project ends by the end of the year 2020, we can mention that among the positive aspects of these academic experiences we have an increase of motivation from the Architecture and urbanism students when using the ICT and in particular gamification of urban scenarios. This happened in students from ETSAB-UPC and from Architecture-LaSalle-Barcelona.

In second place, the graphic courses where Real Time rendering is given and that allowed exploring in a continuous way and designing at the same time, are better evaluated than the use of conventional techniques. The immersive capacities of HMD linked to programs previously described of Real Time rendering are valued when gamification is used. It is also highly valued the realism of the scenarios, since it adds credibility to the proposals; therefore, it is considered an agile tool for exploring ideas suitable to precise contexts. The condition of night lighting in the scenarios is positively evaluated. 
On the negative side: once the urban scenario were completed with all the vegetative environment, facades with textures, etc. they were quite heavy; files with frequency hard to handle were created for the use of traditional virtual simulation programs. The aspect will increase when simulating artificial lighting and its reflection. The use of Real Time rendering programs, are limited to students who own personal laptops for gaming or very powerful and expensive. Very few students have HMD goggles for their designing process. If they use the ones provide by the Institute, their use is time limited. Gamification is considered very useful; however, we lack the possibility of building new virtual objects in real time because we can only use the ones previously defined.

Acknowledgments. This research was supported by the National Program of Research, Development and Innovation aimed to the Society Challenges with the references BIA201677464-C2-1-R \& BIA2016-77464-C2-2-R, both of the National Plan for Scientific Research, Development and Technological Innovation 2013-2016, Government of Spain, entitled "Gamification for the teaching of urban design and the integration of citizen participation (ArchGAME4CITY)", \& "Gamified 3D visualization design with virtual reality systems for the study of the improvement of the user's motivational, social and spatial skills (EduGAME4CITY)". (AEI/FEDER, EU).

\section{References}

1. Blocholm. https://arkdes.se/en/utstallning/blockholm-den-fantastiska-staden. Accessed 12 Feb 2020

2. Play de City. https://www.playthecity.nl/page/3435/play-the-city-foundation. Accessed 12 Feb 2020

3. Cooper Hewitt Org. https://www.cooperhewitt.org/2017/02/20/22454. Accessed 12 Feb 2020

4. Cho, J.Y., Suh, J.: Understanding spatial ability in interior design education: 2D-to-3D visualisation proficiency as a predictor of design performance. J. Inter. Des. (2019). https:// doi.org/10.1111/joid.12143

5. János, K., Gyula, N.K.: The CAD 3D course improves students' spatial skills in the technology and design education. YBL J. Built Environ. 7(1), 26-37 (2019)

6. Lobovikov-Katz, A.: Methodology for spatial-visual literacy (MSVL) in heritage education: application to teacher training and interdisciplinary perspectives. Revista Electronica Interuniversitaria de Formacion Del Profesorado (2019). https://doi.org/10.6018/reifop.22.1. 358671

7. Piga, B.E.A., Salerno, R.: Non-conventional representation for urban design: depicting the intangible. In: Cocchiarella, L. (ed.) ICGG 2018. AISC, vol. 809, pp. 1694-1705. Springer, Cham (2019). https://doi.org/10.1007/978-3-319-95588-9_152

8. Martín-Dorta, N., Saorín, J.L., Contero, M.: Development of a fast remedial course to improve the spatial abilities of engineering students. J. Eng. Educ. (2008). https://doi.org/10. 1002/j.2168-9830.2008.tb00996.x

9. Champion, E.M.: Otherness of place: game-based interaction and learning in virtual heritage projects place and interaction in virtual heritage projects. Int. J. Herit. Stud. (2008). https:// doi.org/10.1080/13527250801953686 
10. Reffat, R.: Revitalizing architectural design studio teaching using ICT: reflections on practical implementations. Int. J. Educ. Dev. Inf. Commun. Technol. (IJEDICT) 3(1), 39-53 (2007)

11. Sariyildiz, S., Der Veer, P.: The role of ICT as a partner in architectural design education. In: Design Studio Teaching EAAE (1998)

12. Valls, F., Redondo, E., Fonseca, D., Torres-Kompen, R., Villagrasa, S., Martí, N.: Urban data and urban design: a data mining approach to architecture education. Telemat. Inform. (2017). https://doi.org/10.1016/j.tele.2017.09.015

13. Navarro, I.: Nuevas tecnologías de visualización para la mejora de la representación arquitectónica en educación. Universidad Ramon Llull, España (2017). https://www. tesisenred.net/handle/10803/403374

14. Sanchez-Sepulveda, M.V., Marti-Audi, N., Fonseca Escudero, D.: Visual technologies for urban design competences in architecture education. In: Proceedings of 7th International Conference on Technological Ecosystems for Enhancing Multiculturality, Leon, Spain, pp. 726-731. ACM, New York (2019). https://doi.org/10.1145/3362789.3362822

15. Gagnon, D.: Video games and spatial skills: an exploratory study. Educ. Commun. Technol. 33(4), 263-275 (1985). https://doi.org/10.1007/BF02769363

16. Sedeno, A.: Video games as cultural devices: development of spatial skills and application in learning. Comunicar 17(34), 183-189 (2010). https://doi.org/10.3916/C34-2010-03-018

17. Martín-Gutiérrez, J., Saorín, J.L., Contero, M., Alcaniz, M.: AR_Dehaes: an educational toolkit based on augmented reality technology for learning engineering graphics. In: 2010 10th IEEE International Conference on Advanced Learning Technologies, pp. 133-137 (2010). https://doi.org/10.1109/ICALT.2010.45

18. Stauskis, G.: Development of methods and practices of virtual reality as a tool for participatory urban planning: a case study of Vilnius City as an example for improving environmental, social and energy sustainability. Energy Sustain. Soc. (2014). https://doi.org/ 10.1186/2192-0567-4-7

19. Calvo, X., et al.: Qualitative assessment of urban virtual interactive environments for educational proposals. In: Proceedings of the Sixth International Conference on Technological Ecosystems for Enhancing Multiculturality, Salamanca, Spain, 24-26 October 2018 (2018)

20. Riera, A.S., Redondo, E., Fonseca, D.: Geo-located teaching using handheld augmented reality: good practices to improve the motivation and qualifications of architecture students. Univ. Access Inf. Soc. 14, 363-374 (2015). https://doi.org/10.1007/s10209-014-0362-3

21. Suwa, M., Tversky, B.: What do architects and students perceive in their design sketches? A protocol analysis. Des. Stud. 18, 385-403 (1997)

22. Sanchez-Sepulveda, M.V., et al.: Innovation in urban design education. In: Proceedings of the Sixth International Conference on Technological Ecosystems for Enhancing Multiculturality, Salamanca, Spain, 24-26 October 2018 (2018)

23. Valls, F., Redondo, E., Fonseca, D., Torres-Kompen, R., Villagrasa, S., Martí, N.: Urban data and urban design: a data mining approach to architecture education. Telemat. Inform. 35, 1039-1052 (2017)

24. Sanchez-Sepulveda, M.V., et al.: Collaborative design of urban spaces uses: from the citizen idea to the educational virtual development. In: Kurosu, M. (ed.) HCII 2019. LNCS, vol. 11568, pp. 253-269. Springer, Cham (2019). https://doi.org/10.1007/978-3-030-22636-7_18 


\section{Author Query Form}

Book ID : 500875_1_En

Chapter No : $\mathbf{2 2}$

\section{Please ensure you fill out your response to the queries raised below and return this form along with your corrections.}

\section{Dear Author,}

During the process of typesetting your chapter, the following queries have arisen. Please check your typeset proof carefully against the queries listed below and mark the necessary changes either directly on the proof/online grid or in the 'Author's response' area provided below

\begin{tabular}{|l|l|r|}
\hline Query Refs. & Details Required & Author's Response \\
\hline AQ1 & $\begin{array}{l}\text { This is to inform you that corresponding author has been identified as per the } \\
\text { information available in the Copyright form. } \\
\text { AQ2 }\end{array}$ & $\begin{array}{l}\text { Please check and confirm if the authors and their respective affiliations have been } \\
\text { correctly identified. Amend if necessary. } \\
\text { As Per Springer style, both city and country names must be present in the } \\
\text { affiliations. Accordingly, we have inserted the country name in the affiliation "3". } \\
\text { Please check and confirm if the inserted country name is correct. If not, please } \\
\text { provide us with the correct country name. }\end{array}$ \\
\hline
\end{tabular}

